\title{
Reaching the 'Not in Education, Employment and Training' (NEET) Generation through Blended TVET: Case Study of Tommy's Lodge in Namibia
}

\author{
Helena Naitsuwe Amadhila* \\ University of Namibia, Private Bag 13301, Windhoek, Namibia
}

\author{
DOI: $\underline{10.36348 / \text { jaep.2021.v05i01.004 }}$ \\ | Received: 09.01.2021 | Accepted: 20.01.2021 | Published: 26.01.2021
}

*Corresponding author: Helena Naitsuwe Amadhila

\section{Abstract}

This paper discusses involvements of apprentices in the work integrated learning programme of the Namibia Training Authority at Tommy's Lodge in Namibia. The paper ties in very well with the theme of the conference and brings out valuable information, lessons and practice regarding the role of Open and Distance Learning (ODL) in honouring the Sustainable Development Goals. The main objective of this study was to document the views of apprentices regarding their involvement in the work integrated learning programme through blended Technical Vocational Education and Training (TVET). A retrospective research design was used, targeting all apprentices actively participating in the work integrated learning programme. A sample of 7 apprentices at Tommy's Lodge were purposively selected. Focused individual interviews (face-to-face) was used as the main approach for data collection. Findings of the study were analysed descriptively. The study provided insight into the work integrated learning programme in Namibia, brought out lessons of the involvement and experiences of apprentices, reflected mentor-apprentice relations, practicable teaching approaches, management of blended TVET programmes. Work integrated learning is a tool for transforming society through knowledge, skills and employment provision. This contributes to social and economic development of the country. Work integrated learning should be strengthened to enhance the knowledge and skills of not in education, employment and training generation. The programme should be implemented in all towns in Namibia. This would ensure contribution to the attainment of Harambee Prosperity Plan, National Development Plans, Agenda 2030 and Sustainable Development Goals.

Keywords: Apprentices, work integrated learning, technical vocational education and training.

Copyright () 2021 The Author(s): This is an open-access article distributed under the terms of the Creative Commons Attribution 4.0 International License (CC BY-NC 4.0) which permits unrestricted use, distribution, and reproduction in any medium for non-commercial use provided the original author and source are credited.

\section{INTRODUCTION}

Education and training are central to the achievement of the 2030 Agenda for Sustainable development, specifically goal 4 .

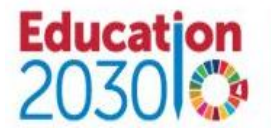

Ensure inclusive and equitable quality education and promote lifelong learning opportunities for all
In an effort to accelerate the provision of education and training, various organisation and institutions have devised plans and strategy to map out processes and procedures for the improvement of education and training. One such organisation is The United Nations Educational, Scientific and Cultural (UNESCO). UNESCO focused on the Technical Vocational Education and Training (TVET) by crafting the UNESCO's Strategy for TVET 2016-2021 to support the efforts of member states to contribute to the transition toward sustainable societies and economies.

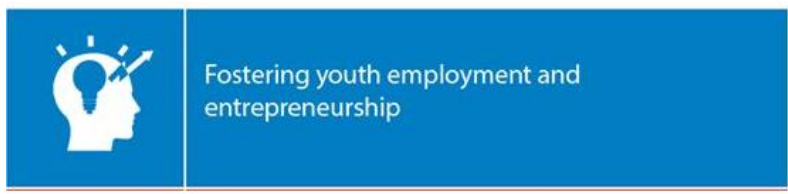

Lack of employable skills has been a long standing issue in Namibia. Several claims were made with regard to youth lacking skills and require support to become employable.

- Entrepreneurs needed to create employment for themselves and others.

- Holistic approach to training and development.

- In 2018, Namibia Training Authority launched a pilot programme called Work Integrated Learning (WIL). 
Helena Naitsuwe Amadhila., J Adv Educ Philos, Jan, 2021; 5(1): 27-31

- Re-introduction of the WIL programme to ensure fully contextualisation of the Apprenticeship programme.

- Draft WIL Policy

- Functional illiteracy.

- Productivity is a challenge.

The NEET rate is defined as the percentage of youth aged 15-34 years who are not in employment and not in education or training.

\section{NEET by region and by sex}

\begin{tabular}{|lrr|}
\hline Region & NLFS 2016 & NLFS 2018 \\
\hline Namibia & 34.5 & 34.9 \\
\hline Urban & 32.5 & 35.0 \\
\hline Rural & 36.9 & 34.8 \\
\hline !Karas & 33.8 & 40.3 \\
\hline Erongo & 25.0 & 32.3 \\
\hline Hardap & 44.1 & 38.6 \\
\hline Kavango East & 37.3 & 41.7 \\
\hline Kavango West & 36.4 & 32.1 \\
\hline Khomas & 31.9 & 34.4 \\
\hline Kunene & 58.6 & 47.5 \\
\hline Ohangwena & 34.0 & 32.7 \\
\hline Omaheke & 33.9 & 44.8 \\
\hline Omusati & 32.4 & 27.1 \\
\hline Oshana & 31.3 & 32.2 \\
\hline Oshikoto & 34.6 & 35.5 \\
\hline Otjozondjupa & 38.6 & 39.8 \\
\hline Zambezi & 39.3 & 30.2 \\
\hline
\end{tabular}

Source: Shimuafeni (2019) [1]

\section{Trends in unemployment rate Overall vs Youth}

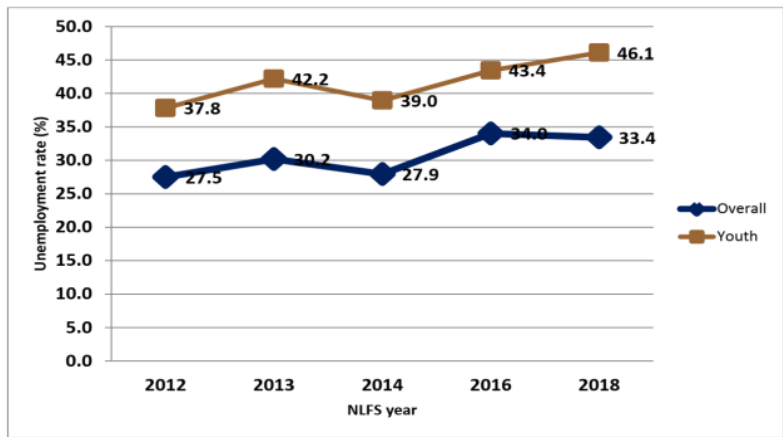

Source: NSA (2018) [2]

The WIL programme was piloted in 2019 with 21 employers recruiting 290 Apprentices [3]. This paper is based on the Work Integrated Learning programme of the Namibia Training Authority at Tommy's Lodge in Namibia. The paper brings out valuable information, lessons and practice regarding the role of Open and Distance Learning (ODL) in honoring the Sustainable Development Goals. It also document the views of apprentices regarding their involvement in the work integrated learning programme through blended Technical Vocational Education and Training (TVET).

\section{MATERIAL AND METHODS}

The paper used the Retrospective research design, targeting all apprentices actively participating in the work integrated learning programme. A sample of 7 apprentices at Tommy's Lodge were purposively selected. Focused individual interviews (face-to-face) was used as the main approach for data collection. Findings of the study were analysed descriptively in order to provide informed discussions, implications and conclusion.

\section{RESULTS AND DISCUSSION}

Demographic data of respondents

\begin{tabular}{|l|l|l|l|l|l|}
\hline Apprentice & Age & Gender & Marital Status & Level of Education & Number of Children \\
\hline Apprentice 1 & 32 & Female & Married & 12 & 2 \\
\hline Apprentice 2 & 22 & Female & Single & 10 & 0 \\
\hline Apprentice 3 & 22 & Male & Single & 12 & 0 \\
\hline Apprentice 4 & 31 & Female & Single & 10 & 2 \\
\hline Apprentice 5 & 21 & Female & Single & 10 & 0 \\
\hline Apprentice 6 & 30 & Female & Single & 12 & 2 \\
\hline Apprentice 7 & 25 & Female & Single & 12 & 1 \\
\hline
\end{tabular}

The table above presents the demographic data of the respondents. According to the information, the majority (six) respondents were female with only one male participating in the programme. Further analysis showed that four respondents were having children from one to two. Additionally, four respondents are holder of grade 12 certificate which is seen as a medium level of education as it can lead to admission at higher institutions of learning if the holder managed to obtain the required points which is normally from twenty and above. Of the seven respondents only one respondent who is married and also seem to be the oldest of other respondents.

Involvement and Experiences

With the opportunity presented to them, the respondents pointed out the following: 
Helena Naitsuwe Amadhila., J Adv Educ Philos, Jan, 2021; 5(1): 27-31

- Great opportunity to learn hands on experience such as cooking, table setting, approach customers, deal with customer anger, waitress, telephone etiquette and computer skills.

- Learn how to work as a team with people of different background

- First time working with many people

- Provide room for controlling emotions

- Focus on the aim at work

- Deal with different clients

- Calm customers down by apologising and assuming as if I am wrong

- Some clients sweet talking me to scam me

- Keep my head up/gut up

- Communicate with guests

- Provide housekeeping services

- Serve guests with a smile

- Taught them about hygiene

- Carried out Front desk duties

- Provide porter services

- Blend drinks for customers

- Engage in internal discussions with mentors

- Learned techniques to enter lodge rooms when cleaning

\section{Mentors-Apprentices relations}

- Respondents revealed that they are not treated equally when it comes to wearing the uniform

- Learned to keep smiling to attract more customers

- Mentors are friendly

- Respondents are able to follow instructions

- Learn how to cope with different situations, learn attitude change

- Mentors do not do briefings and no meetings are held to track progress

- Encourage mentors to first talk to Apprentices before discussing with the Supervisor

- Mentors spend short time with Apprentices

- Mentors sometimes they don't listen and make decisions based on hearsay

- Mentors hear from other people and shut you down

- Respect is important

- There is good/better relations between mentors and Apprentices

- Respondents are a able to follow rules

- Mentors are failing to treat people equal especial on the arrival time to work

- Mentors were found not doing practices with Apprentices

- When problems arise within the work, mentors only talk to the Supervisor without talking to the doer

- Respondents learned leadership skills

\section{Practicable Teaching Approach}

- Enable respondents to learn doing by hand rather than reading

- Respondents gained excellent skills in doing

- The practical's done at the employer enabled demonstration to give a picture of what is being done

- Mentors and Apprentices share real life experience during practical training.

- The approach used by training provider to give exercise and tests every week proved fruitful as Apprentices are kept active during the training session.

- Practical exercises give to Apprentices is commendable as they are able to learn and apply their experiences at the same time.

- Group presentation enable Apprentices to improve their presentation skills

- The provision of reading tasks for the next day would reinforce the knowledge and skills learned in other sessions.

- Apprentices learn how to use computer applications

- Trainers at the training provider use to read in the books during theoretical training.

- Apprentices appreciate the given take home assignments

\section{Management of Blended TVET Programmes}

- WIL is implemented through a multiinstitution approach. This denotes that the regulating body (NTA) is providing the funding to the employer to implement the programme. On the other hand, the employer contracts an accredited training provider to provide theoretical training to Apprentices.

- The management of WIL as a programme enable respondents to acquire knowledge and skills needed in today's world.

- WIL management approach brings about change in somebody to function in this technological world.

- The manner in which WIL as a skills development programme is managed is appreciated by the respondents.

- The integrated approach help to improve on theory and practice at once.

- WIL allow respondents to do everything at once. No one get this type of opportunity. It is not done even at colleges

- Guidance given on providing excellent customer service would ensure customer satisfaction and willingness to return to the business and or recommend the business to other people.

- The supervision done when doing practical's is a good management approach as mentors would be able to see who is doing well in 
Helena Naitsuwe Amadhila., J Adv Educ Philos, Jan, 2021; 5(1): 27-31

which area and which areas need improvement.

- Add valuable details to respondents personal and professional profile

- One respondent pointed out that WIL is a challenging learning process - without this programme, I would have not learned what I have learned.

- WIL programme is valued by apprentices as young people who are neither in employment nor in education or training are at risk of becoming socially excluded - individuals with income below the poverty-line and lacking the skills to improve their economic situation [4].

- Learn by doing promote future readiness resulting in transformative agency to realise the future we want.

- Demonstration: most reliable strategy to facilitate hands-on skills- demonstration by the facilitator, followed by supervised practice [5].

- Multi-institutional approach is crucial for integrated change, long term thinking, youth engagement, thinking communities, meaningful work and functional lifelong learning skills.

- This approach would ensure building a bright future for Namibia by creating skilled workforces, improved productivity and increase the attractiveness of TVET as a field of study.

- Blended TVET is a field that craft a culture of thinking.

- $\quad$ Blended TVET produces competent workforce and practical based solution to overcome unemployment and poverty.

- Blended TVET enable young people to keep learning other skills

- Blended TVET create a platform for striving to do better than yesterday.

- Blended TVET is preparing young people for the $4^{\text {th }}$ Industrial Revolution.

- Blended TVET increase productivity and employment in various sectors.

- Through TVET WIL is training for impact.

- Blended TVET is promoting learning for the world of work.

- Sharing of real-life examples blends in well with the characteristics of lifelong learners [6].

In this unpredictable world characterised by increasing innovation and the need to upskill and reskill the young generation, NEET generation requires continuous funding to ensure sustainability and accessibility. The attainment of national development goals such as Vision 2030, $5^{\text {th }}$ National Development Plan and Harambee Prosperity Plan, Agenda 2030 and Sustainable Development Goals would be determined by various approaches aimed to fulfil and meet the targets inscribed in these various documents.
The non-action on NEET would contribute to the increase of unemployment rate thus widening the skills gaps and inequality among the young generation. An innovative and open learning platforms such as flexible and online learning should be explored to ensure wider access and participation in WIL. WIL should not be commercialised to avoid failure, nonfunctionality and functional illiterates of Apprentices.

\section{CONCLUSION}

- Work Integrated Learning fosters sustainable learning processes;

- Apprentices and employers multipliers to utilise cutting-edge information and communication technologies to disseminate knowledge;

- Technology is a means to enhance learning

- Work Integrated Learning fosters communities of practice that encourage national TVET policies to become more sustainable, more accessible and more dynamic.

- Work Integrated Learning gives second chance to those who could not be absorbed in various learning programmes.

- WIL act as a way of restoring dignity to NEET young people.

- WIL offers practical employable skills that would enable Apprentices to get employed or create employment for themselves and others.

- WIL is creating employment and changing the status quo in the hospitality and tourism industry.

- WIL can boost workplace skills required by industries and customers in this changing world.

- Blended TVET should be intensified as a mode of learning for capacity development;

- Blended TVET should be seen as a catalyst for young people to learn, unlearn and learn as they prepare for future of work;

- Blended TVET is the way to go as it bridges the knowledge divide by breaking down conventions of learning and offering diverse learning paths

- $\quad$ Blended TVET is creating fruitful learning and working environments that nourish young people potentials;

- Blended TVET is strengthening skills and young people's competencies so that they may utilise their knowledge-gained to positively impact themselves and the communities around them

- Multi-stakeholders approach should be emphasised to establish community of practice;

- Funding for TVET should be prioritised as it will contribute to skills development and employment creation in various sectors. 
This study provided an insights on the coordination and management of WIL and would enable all parties involved to reflect on the process, adjust the implementation approach in order to ensure maximum benefits to all intended beneficiaries. It also unpacked solutions to challenges on monitoring, evaluation, learning and reporting of WIL. Furthermore, it would strengthened the continual partnerships between training providers, regulating body and the industry. Finally, the role of workplace skills development and training has been explored and confirmed as the powerful tool to bridge the gap between theoretical training and practical experiences.

To this end, the following are identified factors affecting or influencing the successful implementation and completion of WIL.

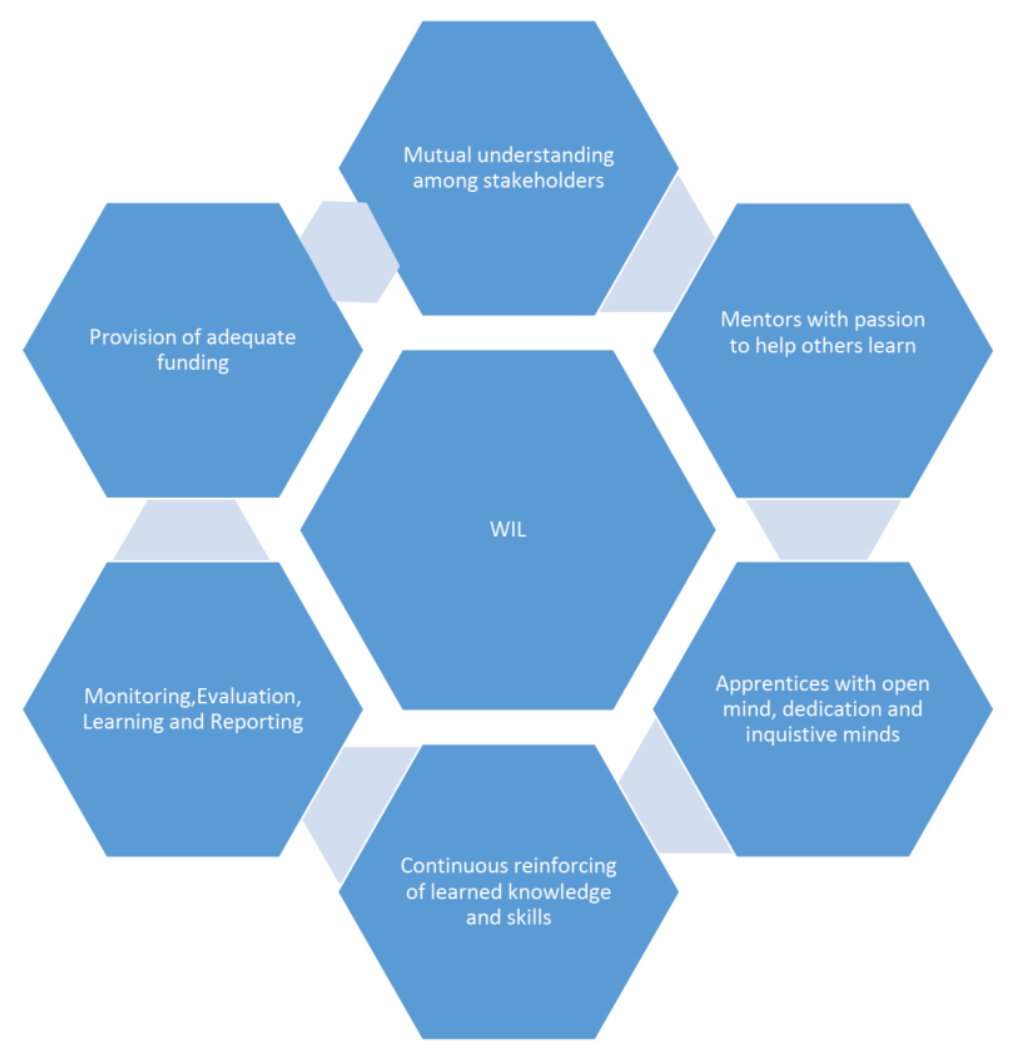

\section{REFERENCES}

1. Shimuafeni, A. (2019). Profile of Unemployment in Namibia. Namibia Statistics Agency. Presentation presented on 16 September 2019 at the Employment Creation Seminar in Windhoek.

2. Namibia Statistics Agency. (2018). In Shimuafeni, A. (2019). Profile of Unemployment in Namibia. Namibia Statistics Agency. Presentation presented on 16 September 2019 at the Employment Creation Seminar in Windhoek.

3. Beukes, J. (2019). Training for Employability and Apprenticeship and Learnership. Namibia Training Authority. Presentation presented on 16
September 2019 at the Employment Creation Seminar in Windhoek.

4. OECD. (2019). Youth not in employment, education or training (NEET) (indicator). doi:10.1787/72d1033a-en (Accessed on 23 September 2019).

5. Hamunyela, M. (2018). Teaching Methods in Adult Education. Centre for Open, Distance and eLearning. Windhoek.

6. Nekongo-Nielsen, H. (2018). Lifelong Learning. Centre for Open, Distance and eLearning. Windhoek. 